\title{
CHEMICAL VARIABILITY AND ANTIMICROBIAL ACTIVITY OF AJUGA LAXMANNII (L.) BENTH. (LAMIACEAE) ESSENTIAL OIL
}

\author{
Jelena S. Lazarević ${ }^{1}$, Aleksandra S. Đorđević ${ }^{2}$, Bojan K. Zlatković3, \\ Gordana S. Stojanović2
}

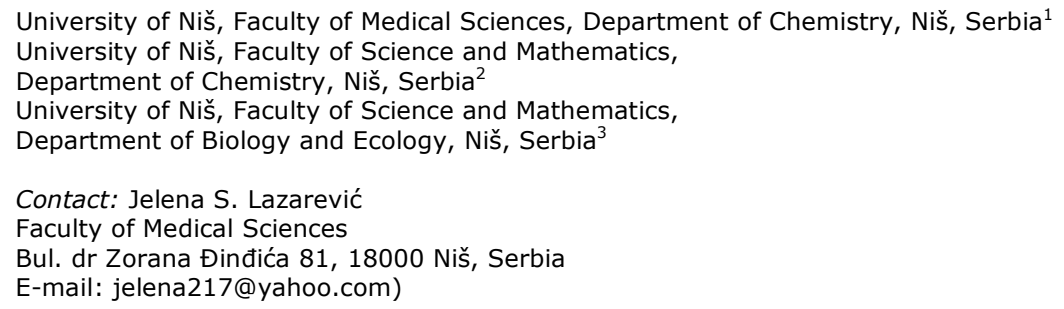

Ajuga plants have had a long history of ethnopharmacological use worldwide. Based on the papers published so far, it seems that there has been a great interest in isolation, structural elucidation and testing of non-volatile Ajuga phytochemicals.

The composition of hydrodistilled aerial part volatiles obtained from six populations of wild-growing A. laxmannii was investigated by means of GC and GC-MS analysis. The oils were screened for in vitro antibacterial and antifungal activity against a panel of laboratory control strains using the broth microdilution assay. The analyses resulted in the identification of one hundred fourteen constituents, accounting for $79.6-97.3 \%$ of the total composition of the oils. The main components of the analyzed samples were (E)-phytol $(5.3-26.1 \%)$, nonacosane $(2.3-25.6 \%)$, coumarin (tr-22.7\%), 1-octen-3-ol $(0-21.2 \%)$, (Z)-3-hexen-I-ol (0-20.5\%), linalool (0-13.7\%) and heptacosane (0.6-10.5\%), which all together contributing more than two thirds to the compounds detected. Among the microorganisms tested the most susceptible strain was Pseudomonas aeruginosa (minimal inhibitory/bactericidal concentration $=1.25 / 2.5 \mathrm{mg} \mathrm{mL}-1$ ). Acta Medica Medianae 2017;56(2):92-101.

Key words: Ajuga laxmannii, essential oil composition, coumarin, antimicrobial activity 